\title{
Role of Protein Kinase A in the Maintenance of Inflammatory Pain
}

\author{
Kochuvelikakam O. Aley and Jon D. Levine \\ Departments of Anatomy, Medicine, and Oral Surgery, Neuroscience and Biomedical Sciences Graduate Programs, \\ National Institutes of Health Pain Center, University of California, San Francisco, California 94143-0440
}

\begin{abstract}
Although the initiation of inflammatory pain (hyperalgesia) has been demonstrated to require the cAMP second messenger signaling cascade, whether this mechanism and/or other mechanisms underlie the continued maintenance of the induced hyperalgesia is unknown. We report that injection of adenylyl cyclase inhibitors before but not after injection of direct-acting hyperalgesic agents (prostaglandin $E_{2}$ and purine and serotonin receptor agonists) resulted in reduction in hyperalgesia, evaluated by the Randall-Selitto paw-withdrawal test. In contrast, injection of protein kinase $A$ (PKA) inhibitors either before or after these hyperalgesic agents resulted in reduced hyperalgesia, suggesting that hyperalgesia after its activation was maintained by persistent PKA activity but not by adenylyl cyclase activity. To evaluate further the role of PKA activity in the maintenance of hyperalgesia, we injected the catalytic subunit
\end{abstract}

Tissue injury results in the production of inflammatory mediators, several of which sensitize primary afferent nociceptors (Martin et al., 1987; Schaible and Schmidt, 1988; Davis et al., 1993; Rueff and Dray, 1993), resulting in hyperalgesic pain (tenderness) (Collier and Schneider, 1972; Moncada et al., 1975; Ferreira et al., 1978; Ferreira, 1981). Inflammatory mediators such as prostaglandin $\mathrm{E}_{2}\left(\mathrm{PGE}_{2}\right)$, adenosine, and serotonin (5-HT) act directly on primary afferent nociceptors to decrease the activation threshold and to increase the response to a constant intensity stimulus (Taiwo and Levine, 1989, 1990, 1992; England et al., 1996; Gold et al., 1996a). A substantial literature suggests that PGE $_{2}-, 5-H T-$, and adenosine-induced hyperalgesia, as well as hyperalgesia induced by tissue damage, is initiated by activation of the adenylyl cyclase (AC)-cAMP-protein kinase A (PKA) second messenger cascade (Taiwo et al., 1989; Taiwo and Levine, 1990, 1991, 1992; Pitchford and Levine, 1991; Khasar et al., 1995; England et al., 1996; Malmberg et al., 1997). Voltage-gated sodium currents may be modulated by PKA. Although the majority of voltage-gated sodium currents modulated by PKA are inhibited, it has been shown that PKA is able to enhance the tetrodotoxin-resistant sodium current (England et al., 1996; Cardenas et al., 1997; Gold et al., 1999), a sodium current found primarily in nociceptors (Akopian et al., 1996; Sangameswaran et al., 1996), that is thought to underlie inflammatory mediator-induced sensitization of nociceptors (England et al., 1996; Gold et al., 1996a; Cardenas et al.,

Received Aug. 27, 1998; revised Dec. 17, 1998; accepted Dec. 22, 1998.

This research was supported by National Institutes of Health Grant NS21647. We thank Drs. Philip Heller and David Reichling for many helpful discussions during the course of these studies and for comments on this manuscript.

Correspondence should be addressed to Dr. Jon D. Levine, National Institutes of Health Pain Center, University of California, San Francisco, C-522, Box 0440, 521 Parnassus Avenue, San Francisco, CA 94143-0440.

Copyright (C) 1999 Society for Neuroscience $\quad 0270-6474 / 99 / 192181-06 \$ 05.00 / 0$ of PKA (PKACS) that resulted in hyperalgesia similar in magnitude to that induced by the direct-acting hyperalgesic agents but much longer in duration ( $>48$ vs 2 hr). Injection of WIPTIDE (a PKA inhibitor) at $24 \mathrm{hr}$ after PKACS reduced hyperalgesia, suggesting that PKACS hyperalgesia is not independently maintained by steps downstream from PKA. In summary, our results indicate that, once established, inflammatory mediatorinduced hyperalgesia is no longer maintained by adenylyl cyclase activity but rather is dependent on ongoing PKA activity. An understanding of the mechanism maintaining hyperalgesia may provide important insight into targets for the treatment of persistent pain.

Key words: adenylyl cyclase; cAMP; hyperalgesia; pain; protein kinase $A$; prostaglandin $E_{2}$

1997) and hyperalgesia (Khasar et al., 1999). Thus, agents that inhibit AC and cAMP-dependent protein kinase (PKA) prevent induction of hyperalgesia by $\mathrm{PGE}_{2}$, CGS21680, and 8-hydroxy-2(di- $N$-propylamino)tetralin (8-OH-DPAT).

Because of the important ramifications for treatment of chronic inflammatory pain, we investigated whether ongoing activity in the cAMP second messenger pathway contributes to maintenance as well as initiation of hyperalgesia and, if so, which steps in the cAMP second messenger cascade determine duration of the hyperalgesia.

\section{MATERIALS AND METHODS}

Animals. Experiments were performed on male Sprague Dawley rats (200-250 gm; Bantin-Kingman, Fremont, CA). Animals were housed in groups of two under a 12:12 hr light/dark cycle. Food and water were available ad libitum. All behavioral testing was done between 10:00 A.M. and 4:00 P.M. Experiments were performed under approval of the Institutional Animal Care Committee of the University of California, San Francisco.

Behavioral testing. The nociceptive flexion reflex was quantified with a Basile Analgesymeter (Stoelting, Chicago, IL), which applies a linearly increasing mechanical force to the dorsum of the rat's hindpaw. The mean baseline threshold was determined as the mean of three readings before the administration of the test agent. The mean baseline threshold, before treatments, for the rats used in these experiments was $109.0 \pm$ $0.45 \mathrm{gm}$ (mean $\pm \mathrm{SEM} ; n=284$ paws). Mechanical threshold was redetermined at three time points $(15,20$, and $25 \mathrm{~min})$ after treatments. The mean of these three readings was considered to be the pawwithdrawal threshold because of drug administration, and this value was used to calculate the percentage change from the baseline threshold for each paw.

The onset of hyperalgesia was determined by assessing 1, 2, 3, 4, and 5 min after injection of a hyperalgesic agent.

Drug administration. The agents used in this study were $\mathrm{PGE}_{2}$ (Sigma, St. Louis, MO); WIPTIDE, 8-OH-DPAT, CGS21680, and SQ22356 


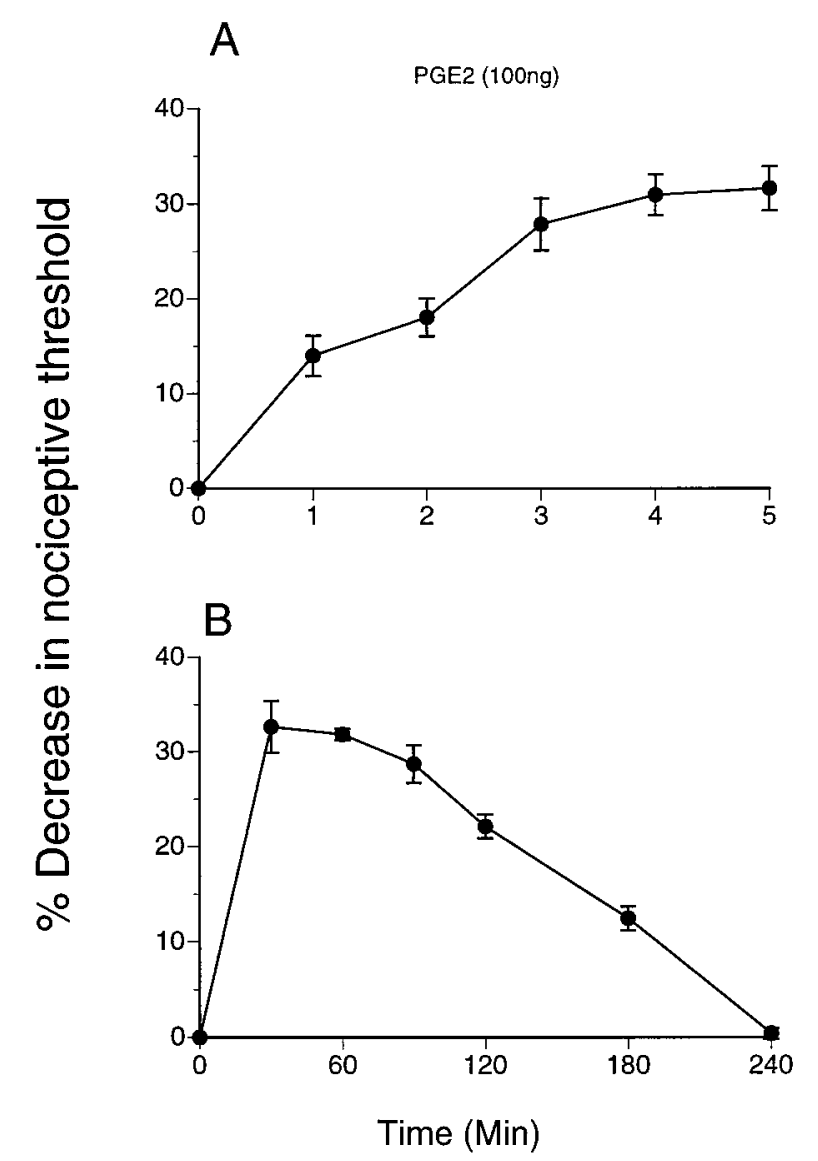

C
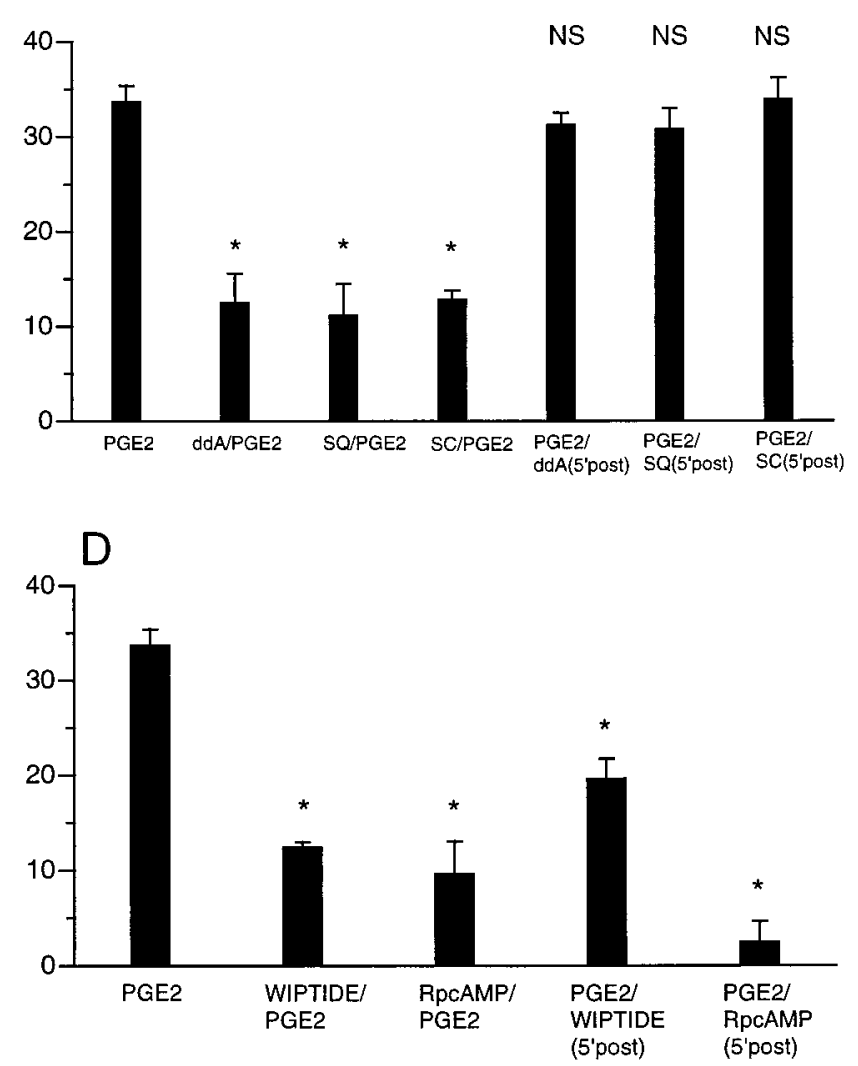

Figure 1. $A$, Latency of onset of $P G E_{2}$-induced mechanical hyperalgesia in the hindpaw of the rat $(n=12)$. $B$, Time course of $P G E_{2}$-induced mechanical hyperalgesia $(n=12)$. $C$, Effect on $P G E_{2}$-induced mechanical hyperalgesia $(n=22 ; p<0.05)$ of the adenylyl cyclase inhibitors $d d A$ and SQ22356 $(S Q)$ when administered before $\left[d d A / P G E_{2}, n=8 ;{ }^{*} p<0.05 ; S Q / P G E_{2}, n=6 ;{ }^{*} p<0.05 ;\right.$ SC19220 $(S C) / P G E_{2}, n=6$; * $\left.p<0.05\right]$ or 5 min after $\left(P G E_{2} / d d A\right.$, $\left.n=10 ; p>0.05 ; P G E_{2} / S Q, n=8 ; p>0.05\right)$ intradermal administration of $P G E_{2}$. D, Effect of PKA inhibitors [WIPTIDE and RpcAMPS (RpcAMP)] when administered before (WIPTIDE/PGE,$\left.n=10 ;{ }^{*} p<0.05 ; R p c A M P / P G E_{2}, n=6 ;{ }^{*} p<0.05\right)$ or 5 min after $\left(P G E_{2} / W I P T I D E, n=10 ;{ }^{*} p<0.05\right.$; $P G E_{2} / R p c A M P, n=6$; $\left.{ }^{*} p<0.05\right)$ intradermal administration of $P G E_{2}$. NS, Not significant.

(Research Biochemicals, Natick, MA); protein kinase A catalytic subunit (PKACS) and RpcAMPS (Calbiochem, La Jolla, CA); dideoxyadenosine (ddA) (courtesy of Dr. Johnson, State University of New York, Stony Brook, NY); and SC19220 (a generous gift from G. D. Searle). The selection of the doses used was based on the dose-response curves determined in this or previous studies (Aley and Levine, 1997, 1998). The stock solution of $\mathrm{PGE}_{2}(1 \mu \mathrm{g} / 2.5 \mathrm{ml})$ was prepared in $10 \%$ ethanol, and further dilutions were made in saline; the final concentration of ethanol was $\leq 1 \%$. PKACS and WIPTIDE were dissolved in saline. All drugs were administered intradermally in a volume of $2.5 \mu \mathrm{l} / \mathrm{paw}$. For test agents with low cell membrane permeability (WIPTIDE and PKACS), coinjection of $2 \mu \mathrm{l}$ of distilled water, to produce hypo-osmotic shock and facilitate cell permeability to these agents, was used (West and Huang, 1980; Burch and Axelrod, 1987; Leidenheimer and Harris, 1991). When combinations of agents were used, they were administered from the same syringe in such a way that the agent mentioned first reached the intradermal site first; similarly, the distilled water preceded agents with low cell membrane permeability. The agents were separated in the syringe by a small air bubble to prevent their mixing in the syringe.

To enhance our ability to analyze a specific second messenger system (that is, to ensure the greatest specificity in block of function), we have (1) used multiple inflammatory mediators known to be direct-acting hyperalgesic agents producing hyperalgesia by the cAMP-PKA second messenger signaling pathway, (2) used the most specific blockers available, (3) used more than one specific blocker of a single target in the second messenger pathway, and (4) used blockers at multiple sites in the same second messenger pathway.
Statistics. Data are presented as mean \pm SEM; statistical significance was determined by ANOVA followed by Scheffe's post hoc test, and $p<$ 0.05 was considered statistically significant.

\section{RESULTS}

Injection of $\mathrm{PGE}_{2}(100 \mathrm{ng})$ resulted in a significant decrease in the nociceptive threshold that reached peak magnitude by $5 \mathrm{~min}$ (Fig. $1 A$ ). Injection of an adenylyl cyclase inhibitor, ddA or SQ22356, before $\mathrm{PGE}_{2}$ reduced $\mathrm{PGE}_{2}$-induced hyperalgesia; however, if injected 5 min after $\mathrm{PGE}_{2}$, ddA or SQ22356 had no effect on the established $\mathrm{PGE}_{2}$ hyperalgesia (Fig. 1C). Similarly, injection of the E-type prostaglandin receptor antagonist SC19220 before but not 5 min after $\mathrm{PGE}_{2}$ attenuated $\mathrm{PGE}_{2}$-induced hyperalgesia (Fig. 1C). Injection of a PKA inhibitor, WIPTIDE or RpcAMPS, before $\mathrm{PGE}_{2}$ also inhibited $\mathrm{PGE}_{2}$-induced hyperalgesia (Fig. 1D); however, unlike the cyclase inhibitors, WIPTIDE or RpcAMPS injected 5 min after $\mathrm{PGE}_{2}$ was also able to inhibit $\mathrm{PGE}_{2}$ hyperalgesia. These results suggest that, $5 \mathrm{~min}$ after its induction, $\mathrm{PGE}_{2}$ hyperalgesia is maintained by PKA activity and that adenylyl cyclase activity is no longer required.

To evaluate the generalizability of this role of PKA in the maintenance of inflammatory hyperalgesia, we determined the effect of adenylyl cyclase and PKA inhibitors on hyperalgesia 


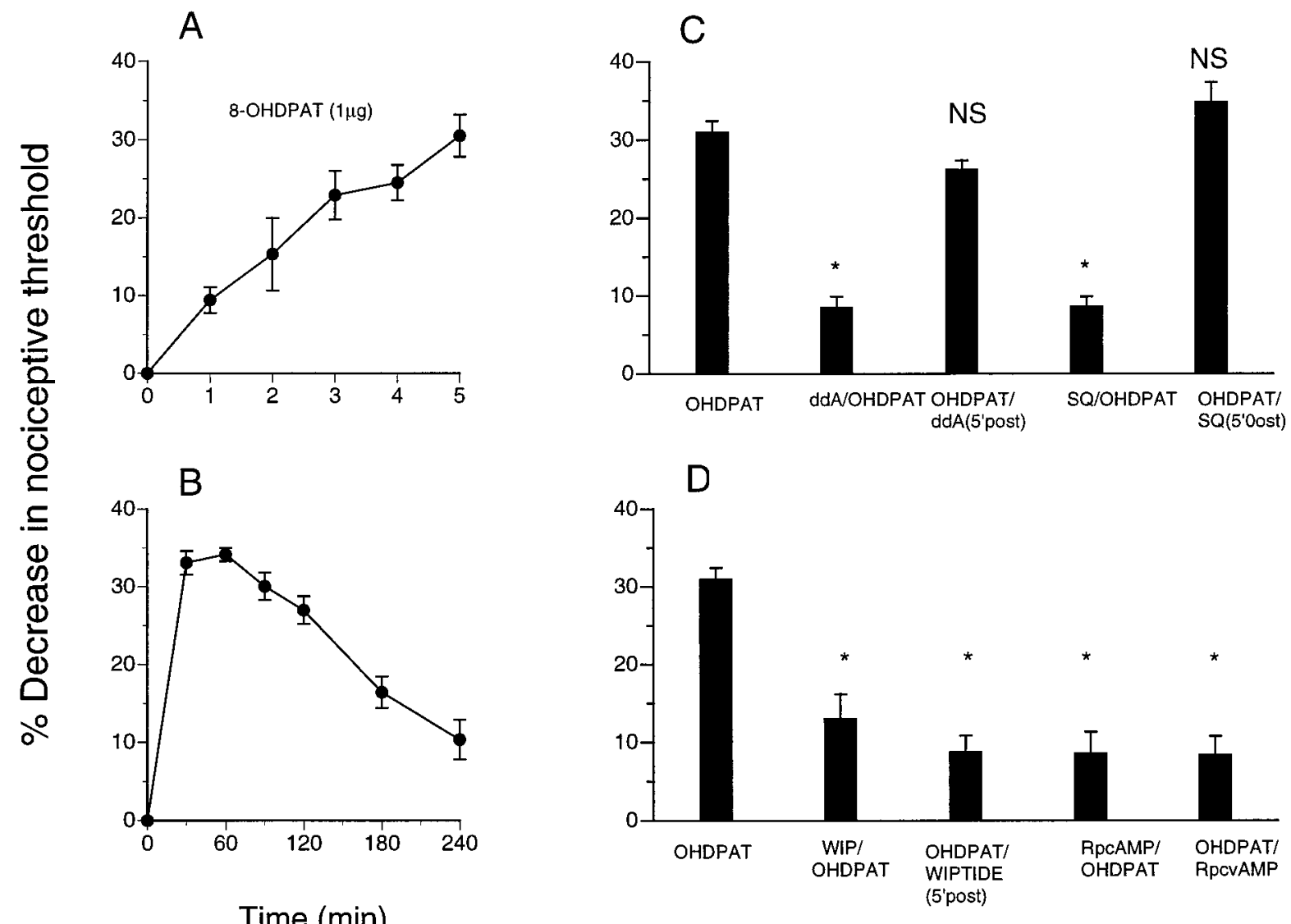

Figure 2. $A$, Latency of onset of direct-acting serotonin agonist [8-OH-DPAT $(O H D P A T)]$-induced mechanical hyperalgesia in the hindpaw of the rat $(n=6) . B$, Time course of $8-O H-D P A T$-induced mechanical hyperalgesia $(n=6) . C$, Effect on $8-O H-D P A T$-induced mechanical hyperalgesia $(n=6$; $p<0.05)$ of the adenylyl cyclase inhibitors $d d A$ and SQ22356 $(S Q)$ when administered before $\left(d d A / O H D P A T, n=6 ;{ }^{*} p<0.05 ; S Q / O H D P A T, n=6\right.$; $\left.{ }^{*} p<0.05\right)$ or 5 min after $(O H D P A T / d d A, n=10 ; p>0.05 ; O H D P A T / S Q, n=6 ; p>0.05)$ intradermal administration of 8 -OH-DPAT.D, Effect of PKA inhibitors [WIPTIDE (WIP) and RpcAMPS (RpcAMP)] when administered before $\left(\right.$ WIP/OHDPAT, $n=6 ;{ }^{*} p<0.05 ; R p c A M P / O H D P A T, n=6 ;{ }^{*} p<$ $0.05)$ or 5 min after (OHDPAT/WIPTIDE, $n=12 ;{ }^{*} p<0.05 ;$ OHDPAT/RpcvAMP, $n=6$; $\left.{ }^{*} p<0.05\right)$ intradermal injection of $8-O H-D P A T$.

induced by two other direct-acting hyperalgesic agents, 8-OHDPAT $\left(5-\mathrm{HT}_{1 \mathrm{~A}}\right.$ serotonin receptor agonist) and CGS21680 ( $\mathrm{A}_{2}$ adenosine receptor agonist) (Taiwo and Levine, 1990, 1992). Injection of 8-OH-DPAT and CGS21680 resulted in a significant decrease in nociceptive threshold (Figs. 2, 3, respectively). Hyperalgesia induced by 8-OH-DPAT or CGS21680 was fully established by $5 \mathrm{~min}$. Injection of the adenylyl cyclase inhibitors ddA and SQ22356 immediately before 8-OH-DPAT and CGS21680 resulted in reduced hyperalgesia; however, if injected 5 min after 8-OH-DPAT and CGS21680, ddA and SQ22356 had no effect on established hyperalgesia. Injection of a PKA inhibitor, WIPTIDE or RpcAMPS, before 8-OH-DPAT or CGS21680 also inhibited induction of hyperalgesia (Figs. 2, 3); injected $5 \mathrm{~min}$ after 8-OH-DPAT or CGS21680, WIPTIDE or RpcAMPS was still able to inhibit hyperalgesia.

To determine whether "exogenous," persisting PKA activity mimics inflammatory mediator-induced hyperalgesia, we injected the PKACS that can be introduced to an intracellular location by a preceding injection of distilled water to produce hypoosmotic shock (Burch and Axelrod, 1987; Taiwo and Levine, 1989; Khasar et al., 1995). Injection of PKACS produced hyperalgesia similar in magnitude to that produced by $\mathrm{PGE}_{2}$ but lasting at least $48 \mathrm{hr}$ (Fig. 4). Injection of WIPTIDE before PKACS inhibited PKACS hyperalgesia (Fig. 4). WIPTIDE was also able to reverse PKACS hyperalgesia when injected $5 \mathrm{~min}, 6 \mathrm{hr}$, or 24 hr after PKACS.

\section{DISCUSSION}

All steps of the cAMP second messenger cascade have been shown to be necessary for the induction of hyperalgesia by directacting agents. However, our results indicate that at 5 min after injection, hyperalgesia is maintained by PKA and is independent of upstream activity in the cAMP-PKA second messenger cascade. The fact that WIPTIDE can inhibit PKACS-induced hyperalgesia when administered at any point during its time course suggests that the hyperalgesia is not maintained by persistence of the changes in the cell downstream from PKA, such as longlasting enhancement of ion channels, such as the tetrodotoxinresistant sodium current, the probable downstream target for PKA in nociceptors mediating sensitization (England et al., 1996; Gold et al., 1996a; Cardenas et al., 1997) and hyperalgesia (Khasar et al., 1999).

Furthermore, because administration of PKACS (essentially an excess of PKA, devoid of its regulatory subunit) produces prolonged hyperalgesia, with a time course consistent with that of metabolic degradation of PKACS (Lee and Steinberg, 1996), the observed time course of hyperalgesia after $\mathrm{PGE}_{2}$ seems to reflect the time course of PKA activation. That PKACS hyperalgesia 
A

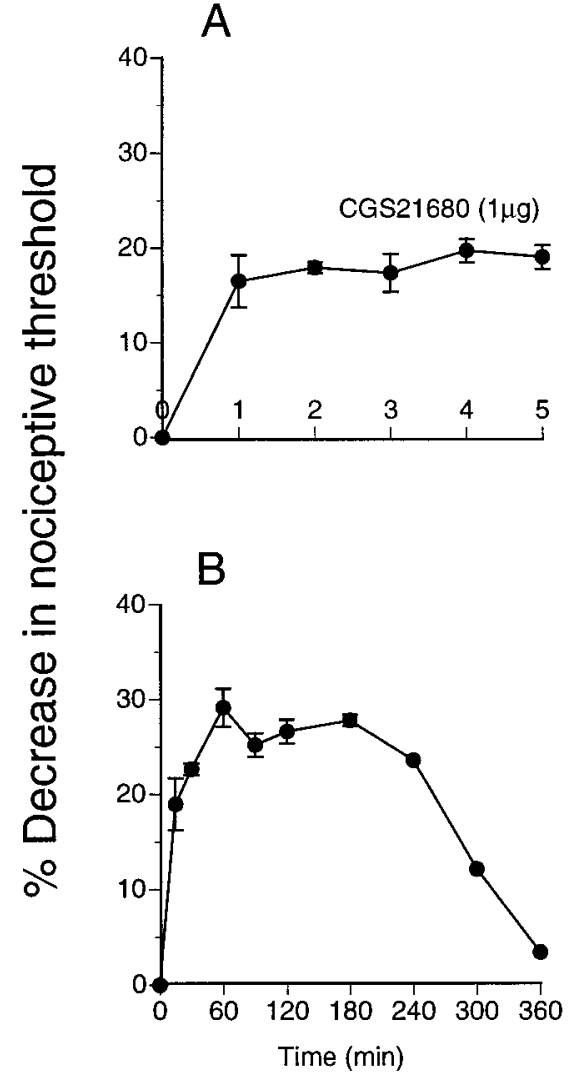

C

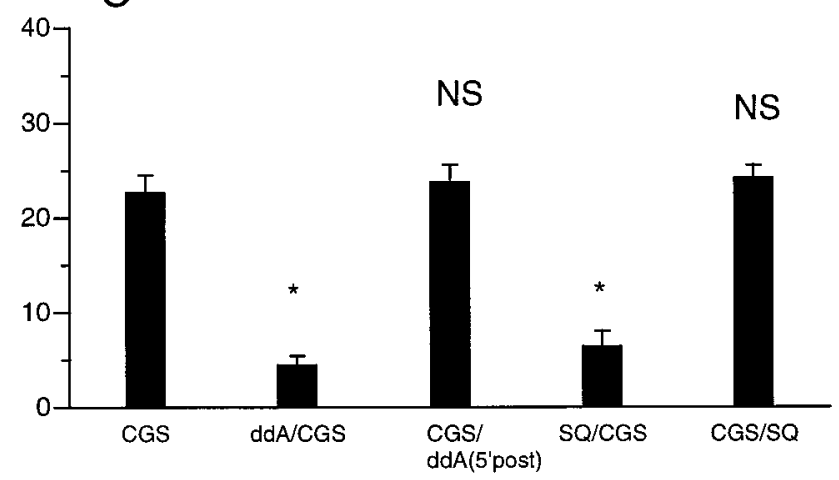

D

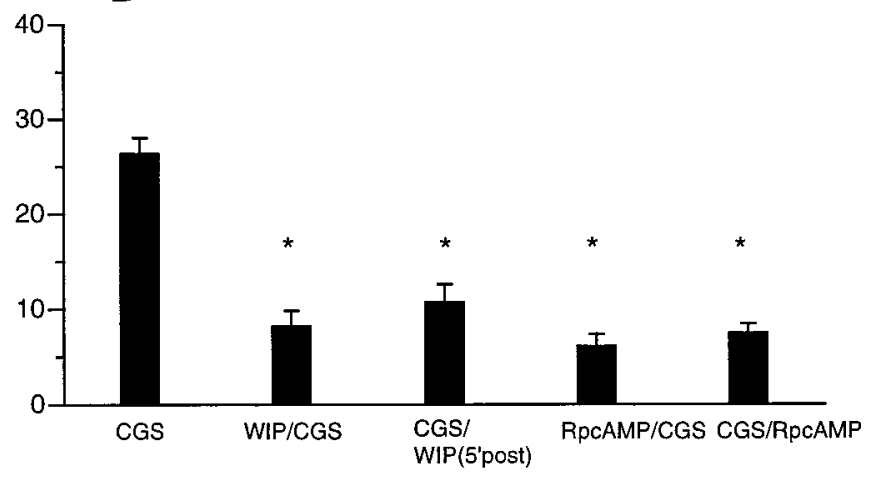

Figure 3. A, Latency of onset of direct-acting adenosine agonist [CGS21680 (CGS)]-induced mechanical hyperalgesia in the hindpaw of the rat $(n=$ 6). $B$, Time course of CGS21680-induced mechanical hyperalgesia $(n=6)$. C, Effect on CGS21680-induced mechanical hyperalgesia $(n=6 ; p<0.05)$ of the adenylyl cyclase inhibitors $d d A$ and SQ22356 (SQ) when administered before $\left(d d A / C G S, n=6 ;{ }^{*} p<0.05 ; S Q / C G S, n=6 ;{ }^{*} p<0.05\right)$ or 5 min after $(C G S / d d A, n=6 ; p>0.05 ; C G S / S Q, n=6 ; p>0.05)$ intradermal injection of CGS21680. D, Effect of PKA inhibitors [WIPTIDE (WIP) and RpcAMPS (RpcAMP)] when administered before $\left(W I P / C G S, n=6 ;{ }^{*} p<0.05 ; R p c A M P / C G S, n=6 ;{ }^{*} p<0.05\right)$ or 5 min after $(C G S / W I P, n=10$; $\left.{ }^{*} p<0.05 ; C G S / R p c A M P, n=10 ; * p<0.05\right)$ intradermal injection of CGS21680.
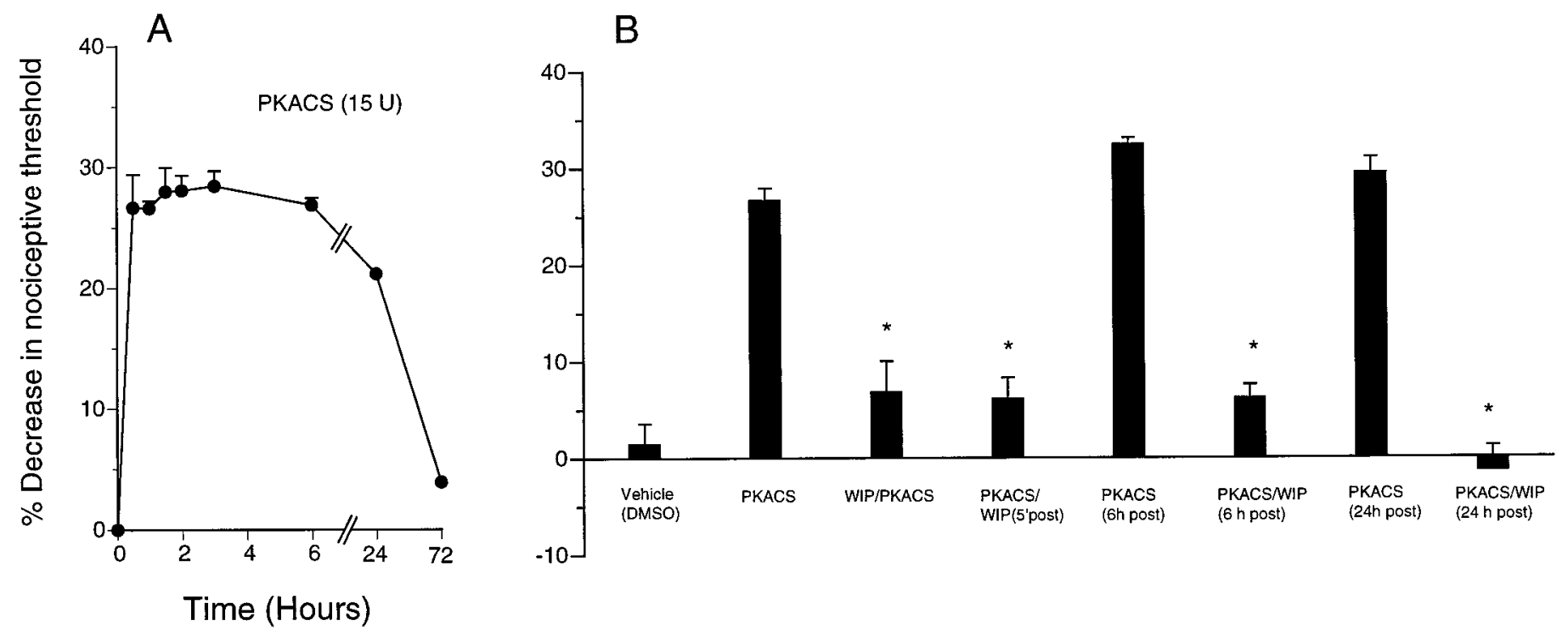

Figure 4. $\quad A$, Time course of $P K A C S(15 \mathrm{U} ; n=12)$-induced hyperalgesia is shown. $B$, Thirty minutes after intradermal injection of $P K A C S(n=12)$ but not its vehicle $(D M S O ; n=6)$, significant hyperalgesia $(p<0.05)$ is induced. WIPTIDE $(W I P)$ injected before $\left(W I P / P K A C S, n=6\right.$; $\left.{ }^{*} p<0.05\right)$ or $5 \mathrm{~min}\left[P K A C S / W I P\left(5^{\prime}\right.\right.$ post $\left.), n=6 ;{ }^{*} p<0.05\right], 6 \mathrm{hr}\left[P K A C S / W I P(6 \mathrm{hr}\right.$ post $\left.), n=6 ;{ }^{*} p<0.05\right]$ or $24 \mathrm{hr}\left[P K A C S / W I P(24 \mathrm{hr}\right.$ post $\left.), n=6 ;{ }^{*} p<0.05\right]$ after $P K A C S$ inhibited $P K A C S$-induced hyperalgesia. 
could be reversed by PKA inhibitors even $24 \mathrm{hr}$ after onset of hyperalgesia further suggests that mechanisms downstream from PKA activity are not effective in the maintenance of the observed hyperalgesia.

If cAMP levels remain persistently elevated, cells undergo changes in their A kinase signaling system; some cells alter the rate of degradation of PKA subunits, and some change the stability of the messages encoding subunits (Spaulding, 1993; Dunbar and Kalinski, 1994; Garrel et al., 1995; Spatz, 1995; Knutsen et al., 1997). Therefore, prolonged hyperalgesia after a sustained exposure to hyperalgesic inflammatory mediators may result from prolonged exposure to cAMP and consequent independently persisting activity of the PKA catalytic subunit because of changes in the ratio of catalytic to regulatory subunits. For example, in nociceptor-like neurons in Aplysia (Clatworthy and Walters, 1993a,b; Dulin et al., 1995; O’Leary et al., 1995), PKA plays an important role in the facilitation that mediates both short- and long-term sensitization (Kandel and Schwartz, 1982; Bailey and Kandel, 1993; Byrne et al., 1993). After exposure to the facilitating neurotransmitter serotonin, protein kinase A activity becomes persistently elevated at basal cAMP levels, because of a decrease in the ratio of the concentration of regulatory to catalytic subunits (Sweatt and Kandel, 1989; Chain et al., 1995). Our demonstration that administration of PKACS produces prolonged hyperalgesia, compatible with its rate of metabolism, suggests that a modification of its metabolism could contribute to chronic hyperalgesic states.

In summary, we have provided evidence for the first time that maintenance of hyperalgesia involves a mechanism distinct from the initiating mechanism. Understanding of the mechanisms maintaining hyperalgesia can provide rationales for novel targets for the treatment of chronic inflammatory pain. Specifically, the results of the present study suggest that continued exposure to inflammatory mediators may not be needed to maintain chronic hyperalgesic pain and, therefore, that the most effective site for therapeutic intervention may not be the cell surface receptor in primary afferent nociceptors but the responsible intracellular second messengers. This observation might also underlie the development of resistance to agents that block the production of hyperalgesic inflammatory mediators, such as the nonsteroidal anti-inflammatory drugs, inhibitors of the synthesis of prostaglandins.

\section{REFERENCES}

Akopian AN, Sivilotti L, Wood JN (1996) A tetrodotoxin-resistant voltage-gated sodium channel expressed by sensory neurons. Nature 379:257-262.

Aley KO, Levine JD (1997) Different mechanisms mediate development and expression of tolerance and dependence for peripheral mu-opioid antinociception in rat. J Neurosci 17:8018-8023.

Aley KO, Levine JD (1998) Nitric oxide signaling in pain and nociceptor sensitization in the rat. J Neurosci 18:7008-7014.

Bailey CH, Kandel ER (1993) Structural changes accompanying memory storage. Annu Rev Physiol 55:397-308.

Burch RM, Axelrod J (1987) Dissociation of bradykinin-induced prostaglandin synthesis from phosphatidylinositol turnover in Swiss 3T3 fibroblasts: evidence for G-protein regulation of phospholipase A2. Proc Natl Acad Sci USA 93:15435-15439.

Byrne JH, Zwartjes R, Homayouni R, Critz SS, Eskin A (1993) Roles of second messenger pathways in neuronal plasticity and in learning and memory. Insights gained from Aplysia. Adv Second Messengers Phosphoprotein Res 27:47-108.

Cardenas CG, Del Mar LP, Cooper BY, Scroggs RS (1997) 5HT4 receptors couple positively to tetrodotoxin-insensitive sodium channels in a subpopulation of capsaicin-sensitive rat sensory neurons. J Neurosci 17:7181-7189.
Chain DG, Hedge AN, Yamamoto N, Liu-Marsh B, Schwartz JH (1995) Persistent activation of cAMP-dependent protein kinase by regulated proteolysis suggests a neuron-specific function of the ubiquitin system in Aplysia. J Neurosci 15:7592-7603.

Clatworthy AL, Walters ET (1993a) Rapid amplification and facilitation of mechanosensory discharge in Aplysia by noxious stimulation. J Neurophysiol 70:1181-1194.

Clatworthy AL, Walters ET (1993b) Activity-dependent depression of mechanosensory discharge in Aplysia. J Neurophysiol 70:1195-1209.

Collier HO, Schneider C (1972) Nociceptive response to prostaglandins and analgesic actions of aspirin and morphine. Nature 236:141-143.

Davis KD, Meyer RA, Campbell JN (1993) Chemosensitivity and sensitization of nociceptive afferents that innervate the hairy skin of monkey. J Neurophysiol 69:1071-1081.

Dulin MF, Steffensen I, Morris CE, Walters ET (1995) Recovery of function, peripheral sensitization and sensory neurone activation by novel pathways following axonal injury in Aplysia californica. J Exp Biol 198:2055-2066.

Dunbar CC, Kalinski MI (1994) Cardiac intracellular regulation: exercise effects on the cAMP system and A-kinase. Med Sci Sports Exercise 26:1459-1465.

England S, Bevan S, Docherty RJ (1996) $\mathrm{PGE}_{2}$ modulates the tetrodotoxin-resistant sodium current in neonatal rat dorsal root ganglion neurones via the cyclic AMP-protein kinase A cascade. J Physiol (Lond) 495:429-440.

Ferreira SH (1981) Inflammatory pain, prostaglandin hyperalgesia and the development of peripheral analgesics. Trends Pharmacol Sci 2:183-186.

Ferreira SH, Nakamura M, Castro MSA (1978) The hyperalgesic effects of prostacyclin and prostaglandin E2. Prostaglandins 16:31-37.

Garrel G, Delahaye R, Hemmings BA, Counis R (1995) Modulation of regulatory and catalytic subunit levels of cAMP-dependent protein kinase $\mathrm{A}$ in anterior pituitary cells in response to direct activation of protein kinase A and C or after GnRH stimulation. Neuroendocrinology 62:514-522.

Gold MS, Reichling DB, Shuster MJ, Levine JD (1996a) Hyperalgesic agents increase a tetrodotoxin-resistant $\mathrm{Na}^{+}$current in nociceptors. Proc Natl Acad Sci USA 93:1108-1112.

Gold MS, Dastmalchi S, Levine JD (1996b) Co-expression of nociceptor properties in dorsal root ganglion neurons from the adult rat in vitro. Neuroscience 71:265-275.

Gold MS, Levine JD, Correa AM (1998) Modulation of TTX-R I $\mathrm{Na}_{\text {a }}$ by $\mathrm{PKC}$ and PKA and their role in $\mathrm{PGE}_{2}$-induced sensitization of rat sensory neurons in vitro. J Neurosci 18:10345-10355.

Kandel ER, Schwartz JH (1982) Molecular biology of learning: modulation of neurotransmitter release. Science 218:433-443.

Khasar SG, Ouseph AK, Chou B, Ho T, Green PG, Levine JD (1995) Is there more than one prostaglandin $\mathrm{E}$ receptor subtype mediating hyperalgesia in the rat hindpaw? Neuroscience 64:1161-1165.

Khasar SG, Gold MS, Levine JD (1998) A tetrodotoxin-resistant sodium current mediates inflammatory pain in the rat. Neurosci Lett 256:17-20.

Knutsen HK, Tasken K, Eskild W, Richards JS, Kurten RC, Torjesen PA, Jahnsen T, Hansson V, Guerin S, Tasken KA (1997) Characterization of the 5'-flanking region of the gene for the cAMP-inducible protein kinase A subunit, TIIbeta, in Sertoli cells. Mol Cell Endocrinol 129:101-114.

Lee SL, Steinberg RA (1996) Pathways for degradation of the catalytic subunit of cAMP-dependent protein kinase differ in wild-type and kinase-negative S49 mouse lymphoma cells. J Biol Chem 271:16553-16558.

Leidenheimer NJ, Harris RA (1991) A transient osmotic permeabilization method for the introduction of impermeant molecules into functional brain membrane vesicles. J Neurosci Methods 40:233-241.

Malmberg AB, Brandon EP, Idzerda RL, Liu H, McKnight GS, Basbaum AI (1997) Diminished inflammation and nociceptive pain with preservation of neuropathic pain in mice with a targeted mutation of the type I regulatory subunit of cAMP-dependent protein kinase. J Neurosci 17:7462-7470.

Martin HA, Basbaum AI, Kwiat GC, Goetzl EJ, Levine JD (1987) Leukotriene and prostaglandin sensitization of cutaneous highthreshold C-mechanonociceptors in the rat. Neuroscience 22:651-659.

Moncada S, Ferreira SH, Vane JR (1975) Inhibition of prostaglandin biosynthesis as the mechanism of analgesia of aspirin-like drugs in the dog knee joint. Eur J Pharmacol 31:250-260. 
Morita K, Katayama Y (1989) Bullfrog dorsal root ganglion cells having tetrodotoxin-resistant spikes are endowed with nicotinic receptors. J Neurophysiol 62:657-664.

O'Leary FA, Byrne JH, Cleary LJ (1995) Long-term structural remodeling in Aplysia sensory neurons requires de novo protein synthesis during a critical time period. J Neurosci 15:3519-3525.

Pitchford S, Levine JD (1991) Prostaglandins sensitize nociceptors in cell culture. Neurosci Lett 132:105-108.

Rizzo MA, Kocsis JD, Waxman SG (1994) Slow sodium conductances of dorsal root ganglion neurons: intraneuronal homogeneity and interneuronal heterogeneity. J Neurophysiol 72:2796-2815.

Rueff A, Dray A (1993) Sensitization of peripheral afferent fibers in the in vitro neonatal rat spinal cord-tail by bradykinin and prostaglandins. Neuroscience 54:527-535.

Sangameswaran L, Fish LM, Koch BD, Rabert DK, Delgado SG, Ilnicka M, Jakeman LB, Novakovic S, Wong K, Sze P, Tzoumaka E, Stewart GR, Herman RC, Chan H, Eglen RM, Hunter JC (1997) A novel tetrodotoxin-sensitive, voltage-gated sodium channel expressed in rat and human dorsal root ganglia. J Biol Chem 272:14805-14809.

Schaible HG, Schmidt RF (1988) Excitation and sensitization of fine articular afferents from cat's knee joint by prostaglandin E2. J Physiol (Lond) 403:91-104.

Spatz HC (1995) Post translational modification of protein kinase A.
The link between short-term and long-term memory. Behav Brain Res 66:79-84.

Spaulding SW (1993) The ways in which hormones change cyclic adenosine $3^{\prime}, 5^{\prime}$-monophosphate-dependent protein kinase subunits, and how such changes affect cell behavior. Endocr Rev 14:632-650.

Sweatt JD, Kandel ER (1989) Persistent and transcriptionallydependent increase in protein phosphorylation upon long-term facilitation in Aplysia sensory neurons. Nature 339:51-54.

Taiwo YO, Levine JD (1989) Prostaglandin effects after elimination of indirect hyperalgesic mechanisms in the skin of the rat. Brain Res 492:397-399.

Taiwo YO, Levine JD (1990) Direct cutaneous hyperalgesia induced by adenosine. Neuroscience 38:757-762.

Taiwo YO, Levine JD (1991) Further confirmation of the role of adenyl cyclase and of cAMP-dependent protein kinase in primary afferent hyperalgesia. Neuroscience 44:131-135.

Taiwo YO, Levine JD (1992) Serotonin is a directly-acting hyperalgesic agent in the rat. Neuroscience 48:485-490.

Taiwo YO, Bjerknes LK, Goetzl EJ, Levine JD (1989) Mediation of primary afferent peripheral hyperalgesia by the cAMP second messenger system. Neuroscience 32:577-580.

West LK, Huang L (1980) Transient permeabilization induced osmotically in membrane vesicles from Torpedo electroplax: a mild procedure for trapping small molecules. Biochemistry 19:4418-4423. 